\title{
A Regenerative Structure to Enhance Collaboration and Technology Transfer between University and Industry in Nigeria
}

\author{
A.I. Obanor ${ }^{1}$, C.C. Kwasi-Effah ${ }^{2}$ \\ ${ }^{I}$ (Department of Mechanical Engineering, University of Benin, P.M.B 1154, Benin City, Nigeria, \\ ${ }_{2}^{2}$ (A Department of Mechanical Engineering, University of Benin, P.M.B 1154, Benin City, Nigeria,
}

\begin{abstract}
The process of collaboration and technology transfer between university and industry in Nigeria cannot be effectively undertaken if there is no formal structure to promote interaction and communication between them. Research has shown that most universities in Nigeria are lacking in fundamental startups for collaboration with industry that is, research groups and facilities. This paper discusses the need for the establishment of a regenerative structure to enhance linkage between university and industry for the purpose of achieving the aforementioned aims. The paper also discusses the functions of various units comprising the regenerative structure and proposes a network of communication between them for effective technology transfer and innovation.
\end{abstract}

Keywords: - collaboration, industry, regenerative structure, technology transfer, university

\section{INTRODUCTION}

A country that pins its prospects of industrial development on assembly line industries has little need for creativity, since it is concerned more with execution rather than design; this is a fact that is likely to keep a country in a lasting state of dependence [1]. This situation has largely been the characteristic feature of most Nigerian industries. Despite the relative simplicity of industrial operations in Nigeria, their performance is inhibited by lack of ancillary or feeder industries for the efficient production of intermediate inputs and spare parts for manufacturing [2]. For instance, the problem of ancillary or feeder industry is clearly demonstrated by the difficulties faced by the automotive industry in Nigeria as a result of improper policy formulation and execution in the establishment of the iron and steel projects in the country [3]. The implication of this is that Nigeria will continue to be technologically dependent on the economically advanced nations through continued importation of finished parts for vehicle assembly. Consequently, the technological manpower in the automotive industry will continue to perform routine assembly tasks and further acquisition of knowledge and skills by them will be hampered if there are no collaborative programmes to facilitate technology transfer from our local universities and research institutes to industry [4]. The aforementioned observations are not limited to the manufacturing sector of the Nigerian industry; they also apply to the extractive sector, particularly oil exploration and refining.

Universities have contributed substantially to the economic and industrial development of technologically advanced countries [5]. On a worldwide level, the positive impact of science and technology education in business and industry has been duly acknowledged $[6,7,8,9]$. For example, the American National Academy of Engineering (NAE) in their assessment of the contribution of academic research to the performance of industrial sector discovered that there has been a growing recognition of the importance of universities and academic research to industrial innovation and performance [10]. In Nigeria, the level of collaboration between universities on the one hand and industry on the other is low [11]. However, some academics in the universities are trying to increase the level of collaboration with industry through individual or joint efforts. This informal collaborative structure of academics in universities with industry in Nigeria results in a low level of technology transfer and interaction between the two institutions. The ultimate effect of this is that the rate of applied scientific and technological research in the universities is reduced and this negatively affects the economic and technological development of the country [3].

In order to substantially increase the level of collaboration and communication between university and industry in Nigeria, this paper strongly advocates the establishment of a regenerative structure to facilitate a formal linkage between the two institutions. The creation and successful operation of this regenerative structure will bring about the following benefits to the university and industry in particular and the nation in general:

(i). Develop human capacity in university and industry

(ii). Solve technological problems identified by staff in the university and industry

(iii). Enable industry to improve the quality of products manufactured by them or enhance the service they provide to the public.

(iv). Stimulate applied scientific and technological research in the university. 
(v). Establishment of more small and medium scale enterprises which will create employment opportunities and jobs in the economy.

(vi). Create wealth and enhance standard of living of Nigerians.

(vii). Promote economic and technological development of the country.

II.

\section{ESTABLISHING A REGENERATIVE STRUCTURE TO LINK UNIVERSITY AND} INDUSTRY

A key requirement in the establishment of the regenerative structure to link university and industry in Nigeria is the availability of manpower with adequate knowledge and skills in both institutions that will drive the process of enhancing effective collaboration and communication between them. Thus the university and industry must have competent and dedicated staff who are properly motivated to undertake all the vital tasks associated with collaboration.

\subsection{FORMATION OF RESEARCH GROUPS IN UNIVERSITIES}

The academic sections of Nigerian universities are usually run under the auspices of a college or faculty-department structure. For universities using the collegiate structure, the college consists of a number of faculties which are further subdivided into departments. For those using the faculty structure, the faculty consists of a number of departments.

Critical requirements for enhancing university-industry collaboration are the formation of various research groups and the establishment of research laboratories in the constituent departments of the faculty. The various research groups should be formed to integrate academic staff and technologists who have specialized in subject areas or course combinations offered in the department. For instance, in the Department of Mechanical Engineering, University of Benin, Benin City, three research groups in the subject areas of Thermo-Fluids, Solid Mechanics and Engineering Design as well as Materials can be formed. Each research group should consist of a number of appropriate staff and headed by a team leader who should preferably be a Professor but certainly not below the rank of an experienced Senior Lecturer.

The research group in a department will be the basic unit to conduct research and hence provide technical solutions to problems identified by staff drawn from both university and industry. The activities of the various research groups and the proper implementation of technical ideas suggested by them will bring about the realization of the benefits enumerated in Section 1 of this paper. The problem solving skills of members of the various research groups will be enhanced. Also, the development of the careers and research capabilities of junior academic staff and technologists of the departments will be actualized. The establishment of properly equipped research laboratories in various departments of the university that are provided with all the requisite materials, machines and tools to enable problem-solving research work to be undertaken by academic staff and technologists is absolutely essential.

\subsection{COLLABORATIVE UNIT IN INDUSTRY}

A very important centre in an industrial establishment seeking to collaborate with a university for effective technology transfer is a collaborative unit. This centre must be properly funded and manned by people with appropriate knowledge and skills to enable it to discharge its functions effectively and achieve the aims for which it was established.

The major tasks of personnel working in the collaborative unit include the following:

(i). Identifying all areas of collaboration between their company and the university

(ii). Identifying specific problems in their company that require technical solutions, which when implemented will lead to the growth of the company, improve the quality of products manufactured or enhance the service rendered to the public.

(iii). liaise with the university on behalf of the top management of the company

(iv). Reporting to the top management of the company the fruits of collaboration on a periodic basis.

The collaborative unit can be expanded to be the research and development centre of the company. This will occur as the company grows and its turnover increases.

\subsection{INNOVATIVE COLLABORATION CENTRE IN UNIVERSITY}

For the purpose of coordinating all collaborative research activities in the various departments and faculties, and therefore manage the process of collaboration with industry, the top management of the university must establish an Innovative Collaboration Centre (I.C.C). This centre which should be headed by a Director must be adequately funded, manned by people who are properly motivated and possess skills and knowledge in the fields of science, engineering, agriculture, pharmacy, law, business administration and management. The Director should be an experienced individual who is capable of handling the complex and multidisciplinary work associated with collaboration and technology transfer. A Deputy Director to assist the Director in carrying 
out his duties should also be appointed. He or She must possess a good deal of expertise and be capable of handling administrative and business work associated with collaboration and technology transfer.

The major functions of the I.C.C are as follows:

(i). liaising with the collaborative unit of industry for the purpose of establishing the framework for collaboration.

(ii). Receiving and collating all technical problems or business proposals from industry.

(iii). Passing business proposals or technical problems needing solutions to the appropriate faculties/departments in the university to conduct the basic or applied research

(iv). Reporting to the top management of the university and collaborative unit in the industry the progress made in the research work on a periodic basis.

\subsection{UNIVERSITY VENTURE STARTUP UNIT}

Some academic staff in Nigerian universities have supervised or carried out research projects which have culminated in the fabrication of various artifacts or machines. These machines that are capable of performing various tasks cannot be mass-produced or undergo further development due to lack of funds. Collaborative work undertaken in conjunction with small and medium scale enterprises or mutually beneficial agreements reached with funding agencies or financial institutions can facilitate the production of these machines for commercial purposes. The profit realized from these collaborative efforts can be used to expand the venture startup unit to research and development centre in the university. These research activities will ultimately increase the level of technological advancement and innovation in the country.

\subsection{NETWORK OF COMMUNICATION}

The various units required to form the regenerative structure that enhance university-industry collaboration have been discussed in Sections 2.1 to 2.4. Fig.1 shows a network of communication between various units of the structure.

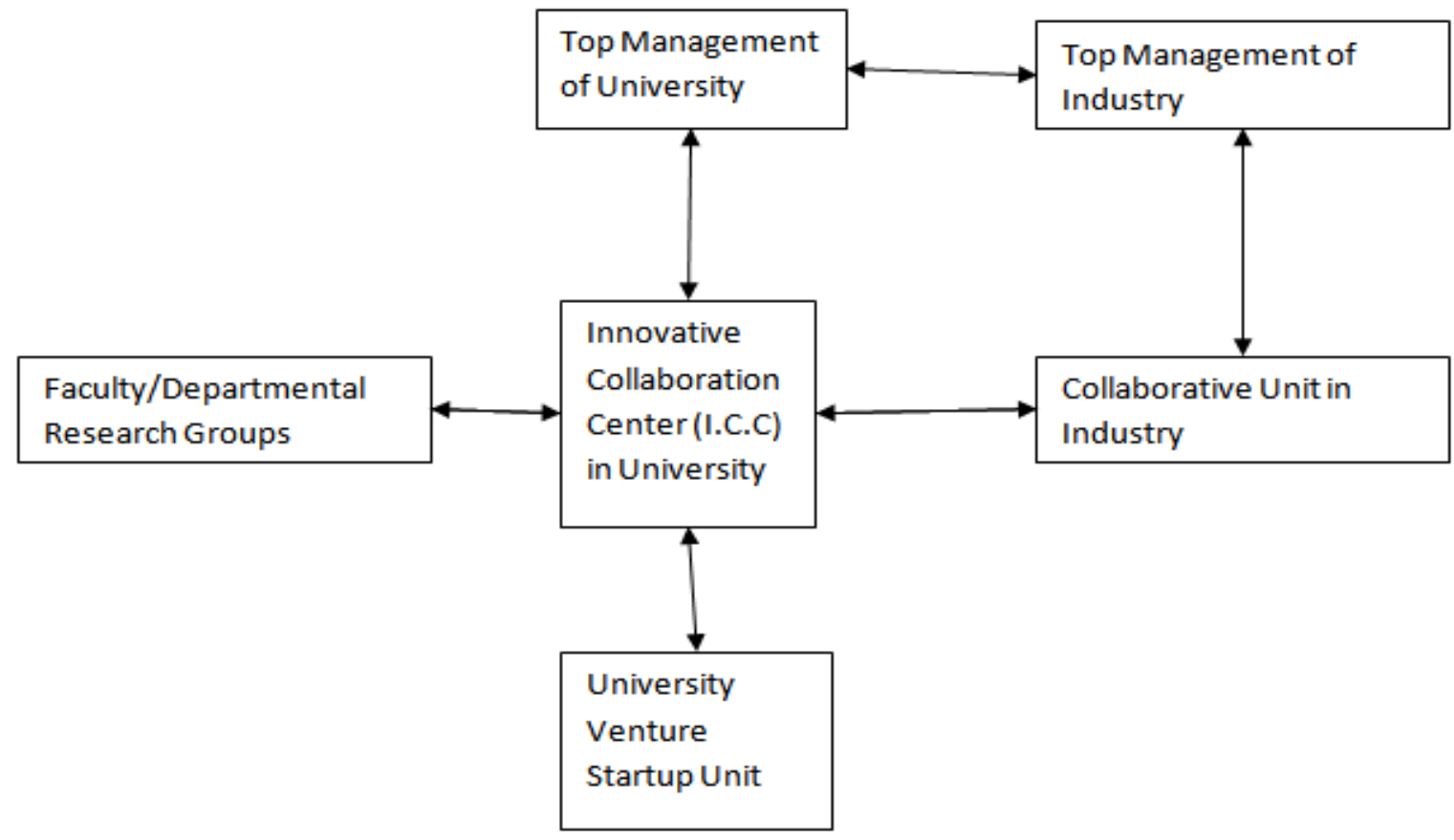

Fig.1 Network of Communication between Various Units of Regenerative Structure

\section{CONCLUSION}

The current level of collaboration between university and industry in Nigeria for the purpose of actualizing mutually beneficial technology transfer between them is low. This situation is mainly attributable to the lack of a formal structure linking both organizations. In order to bring about a turnaround in this state of affairs, this paper has advocated the establishment of a regenerative structure that is domiciled in the university and linked to an appropriate centre in industry. The various units comprising the regenerative structure and their modus operandi have been outlined.

It is hoped that the establishment and proper funding of this formal structure will stimulate collaborative work between university and industry and create the supportive environment that fosters and inspires talented researchers in Nigeria. These research and development activities will serve as a springboard 
for technological innovation and lead to a substantial growth in small and medium scale enterprises that will transform the economy of Nigeria.

\section{REFERENCES}

[1] F. Murray, and S. O'Mahony, Exploring the foundations of cumulative innovation, Implications for Organization Science, 1, 2007, 47-81.

[2] J.I. Victor, and R.H. Christopher, R.H, Contemporary issues in Nigerian industry, Multidisciplinary Journal of Research Development, 1(8), 2007, 22-26.

[3] A.I. Obanor, and C.C. Kwasi-Effah, Technology transfer, intellectual property and university industry collaboration, Technical Report, Department of Mechanical Engineering, University of Benin, 2012.

[4] E.N. Onwuka, Reshaping engineering education curriculum to accommodate the current needs of Nigeria, Educational Research and Review, 4 (7), 2009, 334-339.

[5] A. Bramwell, and D.A. Wolfe, Universities and regional economic development, The Entrepreneurial University of Waterloo, 2008 Research Policy, Florida,1175-1187.

[6] M. Harry, and A.T. Sneed, Bridging the gap between academia and industry, Stevens Award Lecture, 2009, Kaiserslautern, Germany.

[7] D. Abdelkader, The management of technology transfer: views and experiences of developing countries, International Journal of Technology Management, 3 (1-2), 1998, 149-166.

[8] H. Breen, and N. Hing, Improving competitiveness through cooperation: assessing the benefits of cooperative education partnerships in the gaming management, UNLV Gaming Research and Review Journal, 6 (1), 2002, 57-72.

[9] H.N. Abramson, J. Encarnacao, P.P. Reid, and U. Schmoch, Technology transfer systems in the United States and Germany. Washington, D.C.: National Academy Press, 2007.

[10] Academic Research on Industrial Performance, Committee on the Impact of Academic Research on Industrial Performance Technical Report. www.iari.com/ap 2011.

[11] A.I. Obanor, and C.C. Kwasi-Effah, Assessment of university-industry collaboration and technology transfer in schools of engineering and sciences in Nigeria, Nigerian Journal of Technology (NIJOTECH), 32 (2), July 2013, $286-293$. 